\title{
The Studies of Antioxidant and Antimicrobial Potentials of the Leaf Extract of Bauhinia monandra Plant
}

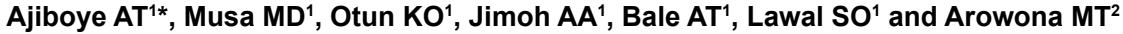 \\ ${ }^{1}$ Department of Chemical, Geological, Physical Sciences, Kwara State University Malete, P.M.B. 1530, Ilorin Kwara State, Nigeria \\ ${ }^{2}$ Deparment of Chemistry, University of Ilorin, PMB 1515, Ilorin, Nigeria
}

\begin{abstract}
In the present study, the dried leaf $(144 \mathrm{~g})$ of $B$. monandra plant was extracted with $95 \%$ ethanol. The crude extract was partitioned into ethyl acetate and $n$-hexane layers to afford fractions with golden brown and greenish yellow colours respectively. The fractions were concentrated and coded EFBM and HFBM. The preliminary phytochemical screening conducted on the crude extract and ethyl acetate fraction (EFBM) revealed the presence of flavonoids, tannins, steroids, terpenoids, saponin, cardiac glycoside and phenols. The antioxidant activity of EFBM and HFBM was evaluated using DPPH radical scavenging assay with ascorbic acid as a reference standard. However, the result of analysis revealed that EFBM exhibited high antioxidant $\left(\mathrm{IC}_{50} \mu \mathrm{g} / \mathrm{mL}=0.010\right)$ activity than $\mathrm{HFBM}\left(\mathrm{IC}_{50} \mu \mathrm{g} / \mathrm{m}=5.564\right)$ and reference standard ascorbic acid $\left(\mathrm{IC}_{50} \mu \mathrm{g} / \mathrm{mL}=30\right)$. The antibacterial activity of EFBM and HFBM against three gramnegative bacterial strains (Eschericha coli, Pseudomonas aeruginosa and Klebsillia oxytoca) was also evaluated and it was found that EFBM exhibited highest antibacterial potential. In contrast to this, HFBM showed negligible or zero activity against all the bacteria strains. The results of the GC-MS analyses of EFBM and HFBM showed the presence of nine different phytochemicals. In EFBM, oleic acid which is classified as monounsaturated omega-9-fatty acid with percentage concentration, $(40.76 \%)$ was the major compound as identified by the GC-MS and 4-hydroxy-5-methyl3-propyl-2-hexanone with percentage concentration, (42.70\%) was identified as the major compound in HFBM. The results of this studies demonstrated that folk medicine can be as effective as modern medicine to combat pathogenic microorganisms. The millenarian use of the leaf of this plant in folk medicine suggests that it represents an economic and safe alternative to treat infectious diseases.
\end{abstract}

Keywords: Phytochemicals; EFBM; HFBM; Antioxidant; Antimicrobial; GC-MS

\section{Introduction}

Antioxidants from plant extract are compounds that demonstrated biological activity which can protect the body from damage caused by free radical-induced oxidative stress [1]. Many of today's diseases that result from imbalance between formation and neutralization of pro oxidant are associated with oxidative stress. Oxidative stress is initiated by free radicals, which seek stability through electron pairing with biological macromolecules such as proteins, lipids and DNA in healthy human cells and cause protein and DNA damage along with lipid peroxidation. These changes contribute to cancer, atherosclerosis, cardiovascular diseases ageing and inflammatory diseases [2,3]. The uses of medicinal herbs are increasingly gaining acceptance even among the literates in the urban settlements, probably because of their effectiveness, affordability, availability, low toxicity, acceptability [4], and also to the increasing inefficiency of many modern drugs used for the control of many infections such as typhoid fever, gonorrhoea, diabetes, tuberculosis as well as increase in resistance by several bacteria to various antibiotics and increase cost of prescription drugs for the maintenance of personal health [5-7]. Bauhinia monandra (Kurz), (family: Caesalpinaceae) is a spreading tree with large leaves, pink and white flowers with one large anther which is elongated and sharply pointed, very persistent pods which split open by explosive mechanism [8]. Bauhinia monandra is commonly known as "cow's foot", Orchid tree, St Thomas tree, Napoleon's plume, Flamboyant, Mariposa and Pink butterfly. In Yoruba tribe of South Western Nigeria, it is known as "abafe" [9]. It is traditionally used for the treatment of diabetes [10]. Its antidiabetic activity has been linked to the presence of antioxidant compounds [11]. Study on the ethylacetate fraction of methanolic leaves extract of B. monandra led to isolation of Quercetrin-3-O-rutinoside and Quercetin [12] and their antioxidant activities had been studied [12]. The activity of freshly crushed leaves of B. monandra towards the treatment of stone fish stings had been studied [13]. A wide range of compounds have been isolated and identified from the species of this genus, this include, lactones, flavonoids, tannins, glycolipids, glucosyl, terpenoids, steroids and quinines [14,15]. 3, 4-dihydroxychalcone-4O- $\beta$-L-arabinopyranosyl-O- $\beta$-D-galactopyranoside $B$. purpurea seeds [16]. However, literature is lacking on the antimicrobial activity of the ethyl acetate fraction, antioxidant and chemical compositions of $\mathrm{n}$-hexane fraction of the leaves extract of B. monandra. Therefore, the present study is an endeavour to find out good natural antimicrobial and antioxidant compounds for the treatment of manifestation caused by microorganism and to establish chemical constituents of ethyl acetate and $\mathrm{n}$-hexane fractions of ethanolic leaf extract of $B$. monandra. In the present study, ethyl acetate and n-hexane fractions of the ethanolic leaves extract of Bauhinia monandra plant were tested for their phytoconstituents, antioxidant using DPPH assay and antimicrobial potential against various pathogenic bacteria strains. The GC-MS analysis of these fractions was also carried out.

\section{Material and Methods}

\section{Material}

Chemicals:1,1-diphenyl-2-picrylhydraxyl (DPPH) and ascorbic acid (Vitamin C) were obtained from Sigma-Aldrich (Germany). Acetic acid, sodium hydroxide, n-Hexane, ethyl acetate, hydrochloric acid $(\mathrm{HCl})$, tetraoxosulphate $(\mathrm{VI})$ acid $\left(\mathrm{H}_{2} \mathrm{SO}_{4}\right)$, chloroform $\left(\mathrm{CHCl}_{3}\right)$

*Corresponding author: Abdulfatai TA, Assistant Lecturer, Kwara State University, Malete, Nigeria, Chemical, Geological and Physical Sciences, Temitope Villa llorin Ilorin, Nigeria, Tel: +2347038866979; E-mail: abdulfatai.ajiboye@kwasu.edu.ng; successjoke@yahoo.com

Received June 19, 2015; Accepted July 07, 2015; Published July 15, 2015

Citation: Ajiboye AT, Musa MD, Otun KO, Jimoh AA, Bale AT, et al (2015) The Studies of Antioxidant and Antimicrobial Potentials of the Leaf Extract of Bauhinia monandra Plant. Nat Prod Chem Res 3: 180. doi:10.4172/2329-6836.1000180

Copyright: @ 2015 Ajiboye AT, et al. This is an open-access article distributed unde the terms of the Creative Commons Attribution License, which permits unrestricted use, distribution, and reproduction in any medium, provided the original author and source are credited. 
ethanol $\left(\mathrm{C}_{2} \mathrm{H}_{5} \mathrm{OH}\right)$ and ferric chloride were obtained from the chemical store of the Department of Chemistry, Kwara State University, Malete, Nigeria. Solvents were redistilled before use while reagents were used without further purification. All other chemicals and reagent were of analytical reagent grade.

Microorganisms: Three-gram negative bacteria namely; Escherichia coli, Klebsiella oxytoca and Pseudomonas aeruginosa used in this study were collected from the department of Microbiology, Kwara State University, Malete, Nigeria. Nutrient agar was used as the growth media for the bacteria.

Instrument: GC-MS analysis: GC-MS analysis on the fractions was carried out in a Shimadzu GC-MS-QP-2010 plus chromatography with capillary column (methyl phenyl siloxane, $60 \mathrm{~mm} \times 0.25 \mathrm{~mm}$ ); ionization detector; carrier gas, helium, flow rate $1.6 \mathrm{~mL} / \mathrm{min}$; column oven temperature $4 \mathrm{~min}$ in $600 \mathrm{c}$ and $8 \mathrm{~min}$ in $160-2800^{\circ} \mathrm{C}$; injection temperature, $2500^{\circ} \mathrm{C}$; viscosity compound time, $0.2 \mathrm{sec}$., washing volume, $8 \mu \mathrm{L}$., split ratio 1.0. The MS parameters were as follows: ion source temp., $2000^{\circ} \mathrm{C}$., interface temperature, $2500^{\circ} \mathrm{C}$, solvent cut time, $2.5 \mathrm{~min}$., scan speed, $769 \mathrm{amu} / \mathrm{s}$, start time, $3.0 \mathrm{~min}$, end time $27 \mathrm{~min}$., start $\mathrm{m} / \mathrm{z}, 40.0$ and end $\mathrm{m} / \mathrm{z}, 400$. Identification was based on the molecular structure, molecular mass and calculated fragments. Interpretation on mass spectrum GC-MS was conducted using the database of National Institute Standard and Technology (NIST 05). The name, molecular weight and structure of the components of the test fraction were ascertained. The spectrum of the unknown component was compared with the spectrum of the component stored in the NIST library.

\section{Methods}

Collection and identification of plant sample: The leaves of Bauhinia monadra were collected from Kwara State University, Malete environ in September, 2014. The plant was identified at the department of Plant biology, Kwara State University, Malete.

Preparation of sample: Fresh leaves of B. monandra were collected and air dried in the laboratory at a temperature of $25^{\circ} \mathrm{C}$ for two weeks. They were subsequently pulverized into fine powder weighing one hundred and forty four grams (144 g)

Extraction: $144 \mathrm{~g}$ of the powdered leaves was extracted with distilled ethanol $(1.4 \mathrm{~L})$ for three days. The extract (greenish dark) was decanted; filtered and concentrated using rotary evaporator at $78^{\circ} \mathrm{C}$ to obtain dark crude extract (16.8 g and $11.6 \%$ ).

Solvent-solvent partitioning of ethanol crude extract of $B$. monandra leaf

Partitioning with n-hexane: $5.0 \mathrm{~g}$ of the crude extract was dissolved in distilled water $(50 \mathrm{~mL})$ and filtered. The filtrate (brown) was taken in a separating funnel and $\mathrm{n}$-hexane $(100 \mathrm{~mL})$ was added. The funnel was shaken vigorously and allowed to stand for a few minutes. The $\mathrm{n}$-hexane fraction was collected. The process was repeated three times. The n-hexane fraction, was concentrated using rotary evaporator at $400^{\circ} \mathrm{C}$ to afford greenish yellow oily liquid which was coded as (HFBM).

\section{Partitioning with ethylacetate:}

$5.0 \mathrm{~g}$ of the crude extract was dissolved in distilled water $(50 \mathrm{~mL})$ and filtered. The filtrate (brown) was taken in a separating funnel and ethylacetate $(100 \mathrm{~mL})$ was added. The funnel was shaken vigorously and allowed to stand for a few minutes. The ethyl acetate fraction was collected. The process was repeated three times. Then ethyl acetate fraction was concentrated using rotary evaporator at $400^{\circ} \mathrm{C}$ to afford golden brown fraction which was coded as (EFBM).
Preliminary phytochemical screening of crude extract and fraction (EFBM)

Chemical tests were carried out on the ethanolic extract of $B$. monandra leaf and its fraction (EFBM) using standard procedures to identify the constituents as described by [17-19]. The specific procedure involved for the evaluation of a particular group of chemicals is mentioned below.

Tannins: One ml of water and 1-2 drops of ferric chloride solution were added in $0.5 \mathrm{ml}$ of extracted solution. Blue colour was taking as indication for tannins.

Flavonoids (Alkaline Reagent Test): Extract was treated with few drops of sodium hydroxide solution. Formation of intense yellow colour, which becomes colourless on addition of dilute acid, indicates the presence of flavonoids.

Steriods: Two $\mathrm{ml}$ of acetic anhydride was added to $0.5 \mathrm{~g}$ ethanolic extract of sample with $2 \mathrm{ml} \mathrm{H}_{2} \mathrm{SO}_{4}$. The colour changed from violet to blue indicating the presence of steroids.

Terpenoids (Salkowski test): Five $5 \mathrm{ml}$ of aqueous extract was mixed in $2 \mathrm{ml}$ of chloroform, and concentrated $\mathrm{H}_{2} \mathrm{SO}_{4}(3 \mathrm{ml})$ was carefully added to form a layer. A reddish brown colouration of the interface was formed to show the presence of terpenoids.

Cardiac glycosides (Keller-Killani test): Five $\mathrm{ml}$ of aqueous extract was treated with $2 \mathrm{ml}$ of glacial acetic acid containing one drop of ferric chloride solution. This was under layered with $1 \mathrm{ml}$ of concentrated tetraoxosulphate (VI) acid. A brown ring of the interface indicates the presence of deoxysugar characteristic of cardenolides.

Alkaloids: Dragendroff's reagent test was conducted for detection of alkaloids: $0.5 \mathrm{~g}$ of aqueous extract was dissolved in $5 \mathrm{ml}$ of $1 \% \mathrm{HCl}$ and the mixture was kept for 2 minutes in water bath. $1 \mathrm{ml}$ of filtrate is treated with dragendroff's reagent. Turbidity or precipitation was taking as indication for presence of alkaloids.

\section{In vitro assessment of the biological activities of HFBM and EFBM}

DPPH antioxidant assay: The ethylacetate and hexane fractions (EFBM and HFBM) from the ethanolic extract of the leaf of B. monandra were subjected to antioxidant test in order to determine the free radical scavenging power. The radical scavenging capacity was determined according to the method described by Cervato et al. with minor modifications. The DPPH was prepared freshly and kept away from light after preparation. $1.0 \mathrm{~mL}$ of fraction with different concentrations $(500,250,200$, and $100 \mu \mathrm{g} / \mathrm{mL})$ was separately mixed with $3.0 \mathrm{~mL}$ of $60 \mu \mathrm{M}$ methanolic solution of DPPH radicals; the mixture was kept at room temperature in the dark for $30 \mathrm{~min}$ and the absorbance measured at $517 \mathrm{~nm}$. Blank experiment was also carried out to determine the absorbance of DPPH before interacting with the fraction. The decrease in absorbance of $\mathrm{DPPH} \cdot$ on addition of test samples in relation to the positive control (Ascorbic acid) was used to calculate the percentage inhibition (\% Inhibition) following the equation:

\section{I \%=100 x (Abscontrol-Abssample) /Abscontrol}

The $\mathrm{IC}_{50}$, (the concentration that inhibited $50 \%$ of the free DPPH radicals) determined.

Data analysis: The 50\% inhibition $\left(\mathrm{IC}_{50}\right)$ was calculated from doseresponse-inhibition nonlinear regression equation of each fraction. The results represent the mean \pm standard error of the mean values of duplicate experiments. IC $_{50}$ values were approximated with statistical significance $\mathrm{p} \leq 0.01$ and with high regression coefficients. 


\section{Antimicrobial Assay}

Preparation of Mueller Hinto Agar (MHA): MHA was prepared according to the manufacturer's instruction $38 \mathrm{~g}$ of MHA was dissolved in $1 \mathrm{~L}$ of sterile distilled water. It was allowed to homogenize before sterilizing inside the autoclave at $121^{\circ} \mathrm{C}$ for 15 minutes. The sterilized MHA was asceptically poured into sterile disposable petri dishes and allowed to set.

Preparation of bacteria innoculum: Innoculum of Pseudomonas aeruginosa, Klebsiella oxytoca and Escherichia coli was prepared according to Kirby-Bauer method. Little quantity of the bacteria culture was suspended in $9 \mathrm{ml}$ sterile normal saline and serially diluted until the colour of the serially diluted bacteria and normal saline resembles the colour of $0.5 \mathrm{McF}$ arland standard. The suspension was swabbed on the surface of the prepared MHA plates.

Antimicrobial susceptibility test: All the innoculated plates were bored at the center with $6 \mathrm{~mm}$ cork borer and each extract was introduced to the hole with the aid of capillary tubes. The plates were allowed to stand uprightly for about 20 minutes before they were transferred to the thermostatically stable incubator. All the plates were incubated at $35 \pm 2^{\circ} \mathrm{C}$ (Normal body temperature).

\section{Results and Discussion}

\section{Results}

Result of the phytochemical screening: The preliminary phytochemical screening conducted on the ethanol extract of $B$. monandra and its ethyl acetate fraction (EFBM) demonstrated the presence of flavonoids, phenols, steroids, alkaloid, glycoside, tannins, saponin and terpenoids as shown in Table 1.

Results of In vitro assessment of the biological activities of HFBM and EFBM

Result of DPPH Antioxidant assay: The result of antioxidant studies of HFBM and EFBM using DPPH free radical scavenging assay with ascorbic acid as reference standard is depicted in Table 2.

Result of the Antimicrobial Assay: The result of antimicrobial activities of HFBM and EFMB against three gram-negative bacteria is as shown in Table 3.

\section{Results of GC-MS analysis}

Result of GC-MS analysis of EFBM: The result of GC-MS analysis of EFBM revealed many phytochemicals, which contribute largely to the medicinal activities of plants. These phytochemicals, with their molecular weight, molecular formulae, percentage area, mass peak and retention index are depicted in Table 4 . The total number of nine compounds were identified and the major compound was oleic acid with percentage composition, (40.76\%), the next abundant compound was found to be hexadecanoic acid with percentage concentration (21.75\%) (Figure 1).

Result of GC-MS analysis of HFBM: The result of GC-MS analysis of HFBM revealed nine different phytochemicals. These compounds with their molecular formulae, molecular weight, retention index, percentage area and mass peak are presented in Table 5 below. The most abundant compound was found to be 4-hydroxy-5-methyl-3-propyl-2hexanone with percentage concentration, $(42.70 \%)$, the next abundant compound was 9-octadecenoic acid (oleic acid), (20.08\%) (Figure 2).

\section{Discussion}

In the present study, the results of phytochemical screening demonstrated the presence of flavonoids, terpenoids, steroids, alkaloid, cardiac glycoside, saponin, tanins and phenols (Table 1). Thus the presence of these phytochemicals in leaf of $B$. monandra plant may be associated with its uses by traditional medicine practitioners in healthcare system in the treatment of diabetics and other infections. From (Table 2), it can be inferred that the EFBM with lower minimum inhibition concentration $\left(\mathrm{IC}_{50} \mu \mathrm{g} / \mathrm{mL}=0.010\right)$ showed significantly high antioxidant activity than HFBM with $\left(\mathrm{IC}_{50} \mu \mathrm{g} / \mathrm{mL}=5.564\right)$ and the reference standard ascorbic acid $\left(\mathrm{IC}_{50} \mu \mathrm{g} / \mathrm{mL}=30\right)$. The antioxidant activity of EFBM is strongly due to the presence of flavonoids and phenols contents as established by qualitative phytochemical screening in this study. Table 3 presents the results of antibacterial activity of EFBM and HFBM against three gram-negative bacteria. It can be deduced that EFBM has broadest spectrum of activity on the tested bacteria. The results show that its activity against Pseudomonas aeruginosa was significantly higher than Escherichia coli, and klebsiela oxytoca. In contrast to this, HFBM showed negligible or zero activity against all the tested bacteria strains. The zero activity of HFBM against tested bacteria strains in this study is in agreement with the findings of [20]. The antimicrobial activity of EFBM may be due to the presence of phytochemicals such as phenols, flavonoids, alkaloids, terpenoids which are naturally biosynthesised in this plant and serve as defense mechanism against any pathogenic microorganisms [21]. The gas chromatogram of EFBM and HFBM depicted the relative concentrations of various phytochemicals getting eluted as a function of retention time (RT). The relative concentration of the isolated component is indicated by the heights of the peaks. The mass spectrometer analysis the compounds eluted at different times so as to identify the nature and the structures of the compounds. The large compounds fragment into smaller compounds giving rise to appearance of peaks at different $\mathrm{m} / \mathrm{z}$ ratios. In this study, nine different compounds were identified in both EFBM and HFBM by GC-MS as depicted in (Tables 4 and 5). In EFBM, fatty acids such as 9-octadecenoic acid (oleic acid), hexadecanoic acid and octadecanoic acid (stearic acid), with percentage concentrations [40.76, 21.75 and 14.0] are the most abundant compounds respectively, both constituting $72.51 \%$ of the total. These compounds also present in HFBM, but at a lower concentration as compared to EFBM. The

\begin{tabular}{|l|l|l|}
\hline Phytochemicals & $\begin{array}{l}\text { Ethanolic Flower Extract Of } \\
\text { B. monandra }\end{array}$ & $\begin{array}{l}\text { Ethylacetate fraction of } \boldsymbol{B} . \\
\text { monandra }\end{array}$ \\
\hline Flavonoids & ++ & ++ \\
\hline Poly phenol & ++ & ++ \\
\hline Cardiac Glycoside & ++ & ++ \\
\hline Terpenoids & ++ & ++ \\
\hline Tannins & ++ & ++ \\
\hline Steroid & ++ & ++ \\
\hline Saponin & ++ & ++ \\
\hline Alkaloids & ++ & ++ \\
\hline
\end{tabular}

Table 1: Result of phytochemical screening of ethanolic leaf extract of $B$. Monandra

\begin{tabular}{|c|c|}
\hline Test fractions & IC $_{\mathbf{5 0}} \boldsymbol{\mu g} / \mathbf{M I}$ \\
\hline HFBM & 5.564 \\
\hline EFBM & 0.010 \\
\hline Ascorbic acid & 30.00 \\
\hline
\end{tabular}

Table 2: $\mathrm{IC}_{50}$ of test fractions using the DPPH assay.

\begin{tabular}{|l|l|l|l|}
\hline Fraction & \multicolumn{3}{|c|}{ Bacteria } \\
\hline & Escherichia coli & Pseudomonas aeruginosa & klebsiela oxytoca \\
\hline EFBM & $16.50 \mathrm{~mm}$ & $25.00 \mathrm{~mm}$ & $11.00 \mathrm{~mm}$ \\
\hline HFBM & $0.00 \mathrm{~mm}$ & $0.00 \mathrm{~mm}$ & $0.00 \mathrm{~mm}$ \\
\hline
\end{tabular}

Table 3: Result of Antimicrobial Assay of EFBM and HFBM. 


\begin{tabular}{|l|l|l|l|l|l|l|}
\hline $\mathbf{s} / \mathbf{n}$ & Compound & RI & MF & MW & \% area & mass peak \\
\hline $\mathbf{1 .}$ & Pentadecanoic acid 14-methyl-methyl ester & 1814 & $\mathrm{C}_{17} \mathrm{H}_{34} \mathrm{O}_{2}$ & 270 & 0.79 & $40,41,57,74,87.101,129,143$ \\
\hline $\mathbf{2 .}$ & Hexadecanoic acid & 1968 & $\mathrm{C}_{16} \mathrm{H}_{32} \mathrm{O}_{2}$ & 256 & 21.75 & $27,41,43,60,73,85,98,115,129,157,171,185,213,256$ \\
\hline $\mathbf{3}$ & 11-octdecenoicacid,methyl ester & 2085 & $\mathrm{C}_{19} \mathrm{H}_{39} \mathrm{O}_{2}$ & 296 & 0.84 & $27,41,55,69,74,87,98$ \\
\hline $\mathbf{4}$ & Oleicacid (9-octadecenoic acid) & 2167 & $\mathrm{C}_{18} \mathrm{H}_{34} \mathrm{O}_{2}$ & 282 & 40.76 & $27,41,55,69,83,97,264$ \\
\hline $\mathbf{5}$ & Octadecanoic acid (steric acid) & 2167 & $\mathrm{C}_{18} \mathrm{H}_{36} \mathrm{O}_{2}$ & 284 & 14.00 & $27,29,40,42,60,73,85,98,115,129,185,241,284$ \\
\hline $\mathbf{6}$ & Octadecane,1-ethyenyloxy(octadecylvinylether) & 2075 & $\mathrm{C}_{20} \mathrm{H}_{40} \mathrm{O}$ & 296 & $5.5 \mathrm{O}$ & $27,29,41,43,57,83,85$ \\
\hline $\mathbf{7}$ & 9,2-octadecadien-1-01,(z,z) & 2069 & $\mathrm{C}_{18} \mathrm{H}_{34} \mathrm{O}$ & 266 & 5.16 & $41,55,67,81,95,110,121,266$ \\
\hline $\mathbf{8}$ & 4-tridecene,(z) & 1321 & $\mathrm{C}_{13} \mathrm{H}_{26}$ & 182 & 8.03 & $27,41,55,69,70,84,98,182$ \\
\hline $\mathbf{9}$ & Pentafloropropionic acid,octadecyl ester & 1971 & $\mathrm{C}_{12} \mathrm{H}_{37} \mathrm{~F}_{5} \mathrm{O}_{2}$ & 416 & 3.12 & $41,48,57,71,97,111,125,252$ \\
\hline
\end{tabular}

Table 4: The result of GC-MS analysis of EFBM.

\begin{tabular}{|l|l|l|l|l|l|l|}
\hline $\mathbf{s} / \mathbf{n}$ & Compound & Ret.Index & $\begin{array}{l}\text { molecular } \\
\text { formular }\end{array}$ & $\begin{array}{l}\text { molecular } \\
\text { weight }\end{array}$ & \% area & mass peak \\
\hline $\mathbf{1}$ & 4-hydroxy-5-methyl-3-propyl-2-hexanone, & 1185 & $\mathrm{C}_{10} \mathrm{H}_{20} \mathrm{O}_{2}$ & 172 & 42.7 & $41,43,58,72,85,100$ \\
\hline $\mathbf{2}$ & 9-octadecenoic acid (oleic acid) & 2175 & $\mathrm{C}_{18} \mathrm{H}_{34} \mathrm{O}_{2}$ & 282 & 20.08 & $27,41,55,69,83,97,123,137,264$ \\
\hline $\mathbf{3}$ & 2,2-dimethyl pentanal & 821 & $\mathrm{C}_{7} \mathrm{H}_{14} \mathrm{O}$ & 114 & 11.26 & $27,41,55,69,83,97,123,137,264$ \\
\hline $\mathbf{4}$ & hexadecanoic acid & 1968 & $\mathrm{C}_{16} \mathrm{H}_{32} \mathrm{O}_{2}$ & 256 & 9.41 & $27,41,43,60,73,129,256$. \\
\hline $\mathbf{5}$ & octadecanoic acid (steric acid) & 2167 & $\mathrm{C}_{18} \mathrm{H}_{36} \mathrm{O}_{2}$ & 284 & 4.98 & $27,41,49,60,73,129,241,284$ \\
\hline $\mathbf{6}$ & hexadecanonic acid 2,3-dihydropropylester, & 2482 & $\mathrm{C}_{19} \mathrm{H}_{32} \mathrm{O}_{4}$ & 330 & 2.93 & $27,41,43,57,74,84,98,134,239,256,299$ \\
\hline $\mathbf{7}$ & 9-octadecenamide,(z)(oleic acid amide), & 2228 & $\mathrm{C}_{18} \mathrm{H}_{35} \mathrm{NO}$ & 281 & 1.15 & $41,55,59,72,85,98,112,126,140,154,238,281$ \\
\hline $\mathbf{8}$ & 9,12-octadecadien-1-o1(z,z) & 2096 & $\mathrm{C}_{18} \mathrm{H}_{34} \mathrm{O}$ & 266 & 2.57 & $41,55,67,81,95,110,121,266$ \\
\hline $\mathbf{9}$ & 2,methyl-z,z,-3,13-octadecadienol & 2104 & $\mathrm{C}_{14} \mathrm{H}_{26} \mathrm{O}$ & 280 & 4.94 & $41,55,67,81,95,109,121,135,149,248$ \\
\hline
\end{tabular}

Table 5: The result of GC-MS analysis of HFBM.

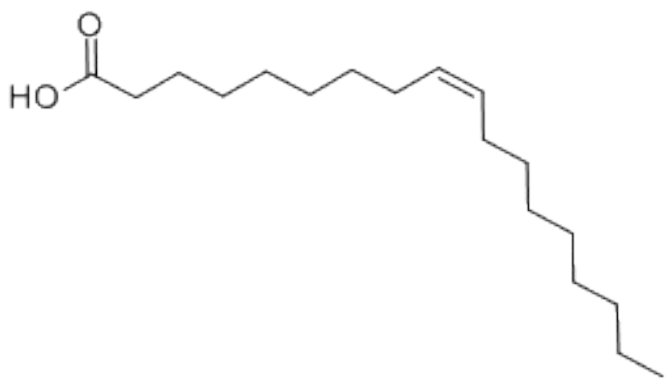

Figure 1: Structure of Oleic acid.

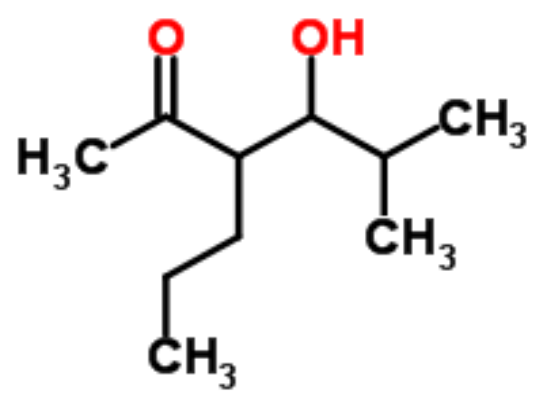

Figure 2: Structure of 4-hydroxy-5-methyl-3-propyl-2-hexanone.

major compound in HFBM was found to be 4-hydroxy-5-methyl-3propyl-2-hexanone and its biological activity is yet to establish. The total percentage concentration of the fatty acids in HFBM was 34.47.

\section{Conclusion}

Bauhinia monandra leaf is a rich source of phytochemicals with proven antioxidant and antimicrobial activities. The phytochemical analysis conducted on B. monandra extract and its ethyl acetate fraction (EFBM) revealed the presence of flavonoids, cardiac glycoside, steroids, phenolics, terpenoids, alkaloid, and saponin. The presence of these phytochemicals confirmed the uses of this plant in folklore medicine for the treatment of many ailments. In vitro studies in this work showed that ethyl acetate fraction of ethanolic leaf extract of B. monandra (EFBM) exhibited high antioxidant and antimicrobial activities than the hexane fraction (HFBM). The antioxidant and antibacterial activities had been attributed to the presence of some bioactive constituents in the EFBM. The most abundant compound found in EFBM as analysed by GC-MS (Table 3) was oleic acid, which is classified as monounsaturated omega-9-fatty acid with percentage concentration 40.76. This compound with other notable fatty acids such as hexadecanoic acid and octadecanoic acid constitute $72.51 \%$ of the total phytochemicals identified in EFBM. However, 4-hydroxy5-methyl-3-propyl-2-hexanone with percentage concentration, (42.70 \%) was the major compound in HFBM. Compounds such as, hexadecanoic acid (9.41\%), 9-octadecenoic acid (oleic acid), (20.08\%), octadecanoic acid (stearic acid), (4.98\%) were also identified but the percentage concentration of fatty acids in HFBM was comparably low to that of EFBM. The results of the present studies support the folkloric usage of the leaf of studied plant and suggest that EFBM possesses compounds with antioxidant and antimicrobial properties that can be further explored for in vivo and clinical studies so as to justify its antioxidant and antimicrobial activities. The results of this studies demonstrated that folk medicine can be as effective as modern medicine to combat pathogenic microorganisms. The millenarian use of the leaf of this plant in folk medicine suggests that it represent an economic and safe alternative to treat infectious diseases.

\section{Reference}

1. Sulaiman S, Ibrahim D, Kassim J, Sheh-Hong L (2011) Antimicrobial and antioxidant activities of condensed tannin from Rhizophora apiculata barks. J. Chem. Pharm. Res 3: 436-444.

2. Braca A, Sortino C, Politi M, Morelli I, Mendez J (2002) Antioxidant activity of flavonoids from Licania icaniaeflora. J Ethnopharmacol 79: 379-381.

3. Maxwell SR (1995) Prospects for the use of antioxidant therapies. Drugs 49: 345-361. 
Citation: Ajiboye AT, Musa MD, Otun KO, Jimoh AA, Bale AT, et al (2015) The Studies of Antioxidant and Antimicrobial Potentials of the Leaf Extract of Bauhinia Monandra Plant. Nat Prod Chem Res 3: 180. doi:10.4172/2329-6836.1000180

4. Akharaiyi FC, Boboye B (2010) Antibacterial and Phytochemical Evaluation of Three Medicinal Plants. Journal of Nat. Prod 3: 27-34.

5. Levi SB (1998) The challenge of antibiotic resistance. Sci Am 278:46-53.

6. Bogaard AEVD, Stobberingh EE (2000) Epidemiology of resistance to antibiotics: Links between animals and humans. International Journal of Antimicrobial Agents 14: 327-335

7. Smolinski MS, Hamburg MA, Lederberg J (2003) Microbial threats to health Emergence, detection, and response. Washington, DC: Institute of Medicine, National Academies Press 203-210.

8. Keay RWJ, Stanfield DP, Onochie CFA (1989) Trees of Nigeria. Clarendo press Oxford. Pp 74-78.

9. Essen Al, Fetuga BL (1989) $\beta$-caroten and some characteristics of under-explotted seed oils of forest trees in Nigeria, Food. Chemistry, England 32:109-116

10. Argolo ACC, Sant'Ana AEG, Pletsch M, Coelho LCBB (2004) Antioxidant activity of leaf extracts from Bauhinia monandra. Bioresour. Technol 95: 229-233.

11. McCune LM, Johns T (2002) Antioxidant activity in medicinal plants associated with the symptoms of diabetes mellitus used by the Indigenous people of the North American boreal forest. J. Ethnopharmacol 82: 197-205.

12. Aderogba MA, Ogundaini AO, Eloff JN (2006) Isolation of two flavonoids from Bauhinia Monandra (Kurz) leaves and their antioxidative effects. Afr. J. Trad. CAM 3: 59-65.
13. Hansworth DK (1990) Traditional medicinal plants of Rarotonga, Cook Islands Part I. Int. J. Crude Drug Res 28: 209-218.

14. Silva KL, Biavatti MW, Leite SN, Yunes RA, Monache F, et al. (2000) Phytochemical and pharmacognostic investigation of Bauhinia forficata Link. $Z$ Naturforsch C 55: 478-480.

15. Mendes BG, Machado MJ, Falkenberg M (2006) Triagem de glicolipídios em plantas medicinais. Rev BrasFarmacogn 16: 568-575.

16. Bhartiyaa HP, Gupta PC (1981) A chalcone glycoside from the seeds of Bahuinia purpurea. Phytochemistry 20: 2051.

17. Sofowara A (1993) Medicinal plant and Traditional medicine in Africa Spectrum Books Ltd, Ibadan, Nigeria. P.289.

18. Trease GE, Evans WC (1989) Pharmacognosy, 11th edn. Brailliar Tiridel can Macmillian publishers.

19. Harborne JB Phytochemical methods London Chapman and Hill, Ltd. Pp.49188. (1973)

20. Binutu OA (1998) Antibacterial activities of some leguminosae plants. Fitoterapia 69: 187-188.

21. Das K, Tiwari RKS, Shrivastava DK (2010) "Techniques for evaluation of medicinal plant products as antimicrobial agents: Current methods and future trends". Journal of Medicinal Plants Research 4: 104-111. 